\title{
SIRT1 activator (SRT1720) improves the follicle reserve and prolongs the ovarian lifespan of diet-induced obesity in female mice via activating SIRT1 and suppressing mTOR signaling
}

Xiao-Ling Zhou', Jin-Jie Xu' ${ }^{2}$, Yan-Hong Ni ${ }^{1}$, Xiao-Chun Chen ${ }^{1}$, Hong-Xia Zhang ${ }^{1}$, Xing-Mei Zhang ${ }^{3}$, Wei-Juan Liu', Li-Li Luo ${ }^{1^{*}}$ and Yu-Cai Fu ${ }^{2^{*}}$

\begin{abstract}
Background: The prevalence of obesity is increasing worldwide and significantly affects fertility and reproduction in both men and women. Our recent study has shown that excess body fat accelerates ovarian follicle development and follicle loss in rats. The aim of the present study is to explore the effect of SIRT1 activator SRT1720 on the reserve of ovarian follicle pool and ovarian lifespan of obese mice and the underlying mechanism associated with SIRT1 and mTOR signaling.
\end{abstract}

Methods: Adult female Kunming mice $(n=36)$ were randomly divided into three groups: the normal control (NC) group ( $n=8$ ), the caloric restriction (CR) group (fed $70 \%$ food of the NC group, $n=8$ ) and the high-fat diet (HF) group (fed a rodent chow containing $20 \% \mathrm{fat}, \mathrm{n}=20$ ). After 4 months, the HF mice were further randomly divided into three groups: the control high-fat diet ( $C H F, n=8)$ group (treated every day with an intraperitoneal injection of vehicle), the SRT1720 (SRT, $\mathrm{n}=6)$ group (treated every other day with an intraperitoneal injection of SRT1720 (50 mg/kg)), the SRT1720 and nicotinamide (NAM, $\mathrm{n}=6$ ) group (treated every other day with an intraperitoneal injection of SRT1720 $(50 \mathrm{mg} / \mathrm{kg})$ and every day with an intraperitoneal injection of nicotinamide $(100 \mathrm{mg} / \mathrm{kg})$ ). After 6 weeks of treatment, ovaries were harvested for histological and Western blotting analyses.

Results: The body weight, ovary weight and visceral fat in the SRT group were significantly lower than those in the CHF group at the end of treatment. Histological analysis showed that the SRT mice had significantly greater number and percentage of primordial follicles, but lower number and percentage of corpora lutea and atretic follicles than the CHF mice and NAM mice. Western blot analysis demonstrated that the levels of SIRT1, SIRT6, FOXO3a and NRF-1 protein expression significantly increased in the ovaries of SRT mice, whereas those of mTORC1, p-mTOR, p-p70S6K, NFkB and p53 decreased compared to the CHF and NAM mice.

Conclusions: Our study suggests that SRT1720 may improve the follicle pool reserve in HF diet-induced obese female mice via activating SIRT1 signaling and suppressing mTOR signaling, thus extending the ovarian lifespan.

Keywords: SRT1720, Nicotinamide, Ovarian development, Obesity, Mice

\footnotetext{
*Correspondence: Iuolili6606@163.com; ycfu@stu.edu.cn

'Department of Gynaecology and Obstetrics of the First Affiliated Hospital, Shantou University Medical College, Shantou, Guangdong Province 515041, People's Republic of China

${ }^{2}$ Laboratory of Cell Senescence, Shantou University Medical College, 22 Xin Ling Rd, Jinping District, Shantou, Guangdong Province 515041, People's

Republic of China

Full list of author information is available at the end of the article
}

\section{Biomed Central}

(c) 2014 Zhou et al.; licensee BioMed Central Ltd. This is an Open Access article distributed under the terms of the Creative Commons Attribution License (http://creativecommons.org/licenses/by/4.0), which permits unrestricted use, distribution, and reproduction in any medium, provided the original work is properly credited. The Creative Commons Public Domain Dedication waiver (http://creativecommons.org/publicdomain/zero/1.0/) applies to the data made available in this article, unless otherwise stated. 


\section{Introduction}

The prevalence of obesity has steadily increased over the past three decades all over the world, and newly released data has showed that nearly one-third of the world's population is obese or overweight [1]. Significant evidence suggests that excess body fat is a major risk factor for non-insulin-dependent diabetes mellitus, cardiovascular diseases, cancers, gastrointestinal diseases, arthritis and metabolic disorders [2], as well as disruptions in reproduction [3]. Excess body fat (particularly abdominal obesity) is closely related to irregular menstrual cycles, reduced spontaneous conception and increased risk of miscarriage $[4,5]$. A recent study indicated that obesity negatively impacted oocyte and embryo quality [6]. In parallel to findings in human beings, diet-induced obese mouse studies have shown a wide range of negative reproductive phenotypes in addition to poor outcomes in the offspring from these mice [7-9]. Additionally, our previous study demonstrated that obesity accelerated ovarian follicle development and follicle loss in female rats [10]. Female fertility is determined by the size of the primordial follicle pool formed during fetal life and by the rate of depletion of the pool after birth [11]. In addition to reduced ovarian complement, early depletion of the follicular pool due to excess follicular activation and/or atresia can occur and results in infertility $[12,13]$. Childhood obesity also has a negative effect on reproduction, which may lead to early onset of puberty, menstrual irregularities during adolescence and polycystic ovary syndrome [14]. These studies shed light on the negative effects of obesity on the reproductive functions in females. However, how obesity affects the ovarian follicle development, and the underlying mechanisms remain elusive.

Anti-obesity management can improve cardiovascular and diabetes risk factors in overweight and obese individuals [15], as well as reproduction disease [16]. Resveratrol, a natural SIRT1 activator, can partly mimic effects of calorie restriction (CR) in mice and obese humans $[17,18]$. Resveratrol has anti-aging effect and also beneficial effects of cardiovascular and metabolic system $[19,20]$. Consistently, it prolongs the ovarian lifespan and protects against age-associated infertility in rodents [21,22]. However, resveratrol is not a specific activator of SIRT1, and it can also activate other signaling pathways [23]. SRT1720, a specific activator of SIRT1, is 1000 times more potent than resveratrol $[24,25]$. However, whether SRT1720 could affect ovarian follicle development and promote the follicle pool reserve through activating SIRT1 signaling is unknown. In the present study, we used a high-fat diet induced obese mouse model to characterize the effect of SRT1720 on ovarian follicle development in adult obese animals and to investigate the associated mechanism with SIRT1 and mTOR signaling.

\section{Materials and methods Materials}

Primary and secondary antibodies applied in this study were introduced as follows: SIRT1, FOXO3a, NRF-1, mTOR, phospho-mTOR, phospho-p70S6 kinase $\alpha$, NF-kB and p53 antibodies were obtained from Santa Cruz Biotechnology, USA; SIRT6 antibody was purchased from Abcam, UK; $\beta$-actin was obtained from Zhongshan Golden Bridge, Beijing, China; Secondary antibodies to mouse and rabbit IgG were purchased from Sigma, USA. SRT1720 was obtained from Selleck, USA, and nicotinamide was obtained from Sigma, USA. They were dissolved in double distilled water containing $10 \%$ ethanol and $40 \%$ polyethylene glycol 400 for intraperitoneal injection [25].

\section{Animals and regiments}

Thirty six female Kunming mice ( 4 weeks old, $20 \pm 2$ g) were purchased from Shantou University Medical College Laboratory Animal Center. After 4 weeks of adaptation, mice were randomly divided into three diet groups: the normal control (NC) group $(\mathrm{n}=8)$ fed ad libitum a standard rodent chow (4.84\% fat,7.34\% fiber, $20.11 \%$ protein, plus all necessary vitamins and minerals, $\mathrm{GE}=3.5 \mathrm{Kcal} / \mathrm{g}$ ), the high-fat (HF) group $(\mathrm{n}=20)$ fed ad libitum a high-fat chow purchased from Shanghai Laboratory Animal Center (20.0\% fat, $21.0 \%$ protein, $43.5 \%$ carbohydrate, plus all necessary vitamins and minerals, GE $=4.383 \mathrm{kcal} / \mathrm{g}$ ), and the CR group $(n=8)$ fed $70 \%$ of the food intake from the NC group. We recorded daily food intake of the $\mathrm{NC}$ mice, and the food supply of the CR group was adjusted accordingly. After 4 months of high-fat diet treatment, the HF mice were further randomly divided into three groups: the control high-fat diet $(\mathrm{CHF})$ group $(n=8)$ (treated every day with an intraperitoneal injection of vehicle), the SRT1720 (SRT) group $(\mathrm{n}=6)$ (treated every other day with an intraperitoneal injection of SRT1720 (50 mg/ $\mathrm{kg})$ ), the nicotinamide and SRT1720 (NAM) group $(n=6)$ (treated every other day with an intraperitoneal injection of SRT1720 $(50 \mathrm{mg} / \mathrm{kg}$ ) and every day with an intraperitoneal injection of nicotinamide $(100 \mathrm{mg} / \mathrm{kg}))$. They were maintained on these treatments for 6 weeks.

All of the mice were housed 2 in steel cages in a room with an ambient temperature of $22^{\circ} \mathrm{C} \pm 2^{\circ} \mathrm{C}$ and a 12-hour light:12-hour dark cycle and had free access to tap water. All animal protocols were approved by the Institutional Animal Care and Use Committee of Shantou University Medical College.

\section{Estrous cycle analysis}

Vaginal smears of all mice were taken daily between 9:00 and 10:00 A.M. Vaginal cells were collected via a sterile cotton swab moistened with normal saline, and then placed on a clean glass slide. Stages were analyzed under the microscope and assessed based on vaginal cytology 
[26]. A 4 to 5-day estrous cycle was determined to be a regular cycle, and a cycle duration of $>5$ days or $<4$ days was considered to be an irregular cycle [27].

\section{Preparation of ovarian sections}

The mice were weighed every four weeks. After 24 weeks, mice were anaesthetized at the diestrus phase of the cycle with pentobarbital sodium at $40 \mathrm{mg} / \mathrm{kg}$ body weight, and sacrificed by cervical dislocation. Mouse perirenal fat was isolated and weighed and expressed as visceral fat index. Both ovaries of each mouse were removed and weighed. One ovary was stored at $-80^{\circ} \mathrm{C}$ for Western blot analysis, and the other one was fixed in $4 \%$ paraformaldehyde at room temperature for 4 hours, flushed under running water for 3 hours, then dehydrated through a series of concentrations of ethanol, cleared in xylene and embedded in paraffin. Ovarian sections of $4 \mu \mathrm{m}$ were prepared for hematoxylin and eosin (HE) staining.

\section{HE staining and follicle classification}

The sections were deparaffinized in xylene, hydrated with decreasing alcohol concentrations, and stained with HE using standard protocols. Sections were mounted using Canada balsam and observed under a light microscope. Five representative sections from each ovary were selected for follicle counting, with each observed section separated by a distance of over $80 \mu \mathrm{m}$. Follicles were classified according to a previous study [28] as follows: primordial follicle (an oocyte surrounded by one layer of flattened granulosa cells), primary follicle (an oocyte surrounded by one layer of cuboidal granulosa cells), secondary follicle (two or three layers of cuboidal granulosa cells with no antral space), and antral follicle (more than four layers of granulosa cells with one or more independent antral spaces). In some cases, antral follicles had no antral space in cross-section analysis, but were considered antral if they contained more than five granulosa cell layers. Follicles were defined as either healthy (intact germinal vesicle and nucleolus, oocyte with no more than three cytoplasmic vacuoles, intact basallamina) or atretic (apoptotic). If antral follicles contained at least twenty apoptotic granulosa cells (defined by the apoptotic bodies in the granulosa cell layer), disorganized granulosa cells, a fragmentation of the oocyte nucleus, or a degenerating oocyte, they were considered atretic [29].

\section{Western blot analysis}

Mouse ovaries were homogenized in RadioImmunoprecipitation Assay (RIPA) and Phenylmethanesulfonyl fluoride (PMSF) with a Teflon-glass homogenizer on ice. After centrifugation $\left(12,000 \mathrm{rpm}, 15 \mathrm{~min}\right.$ at $\left.4^{\circ} \mathrm{C}\right)$, the supernatants were collected for protein analysis. Protein concentrations were determined by the BCA Protein Assay Kit (Beyotime). The protein samples were separated by SDS-PAGE and transferred onto nitrocellulose membranes (BioTrace ${ }^{\mathrm{TM}}$ NT, USA). The membranes were blocked in 5\% nonfat dry milk in Tris-Buffered-Saline with Tween 20 (TBST) for 1 hour and incubated with a primary antibody against SIRT1 (1:200 dilution), FOXO3a (1:200 dilution), SIRT6 (1:500 dilution), NRF1 (1:400 dilution), mTOR (1:200 dilution), phospho-mTOR (1:500 dilution), phospho-p70S6 kinase $\alpha$ (1:500 dilution), NFkB (1:600 dilution), p53 (1:600 dilution) or $\beta$-actin (1:5000 dilution) over-night at $4^{\circ} \mathrm{C}$, followed by the incubation with a horseradish peroxidase-conjugated anti-rabbit or antimouse antibody (1:5000 dilution) at room temperature for 1 hour. Bands were visualized with a chemiluminescence reagent (Thermo Fisher Scientific, USA). Band intensities were analyzed using the Quantity One software (Bio-Rad Laboratories Pty. Ltd.). $\beta$ - actin was used as a loading control.

\section{Statistical analysis}

All results are expressed as the means \pm S.E.M and analyzed by the SPSS 17.0 software. A one-way ANOVA was used to compare the data among groups. A $P$-value less than 0.05 was considered as statistical significance $(P<0.05)$.

\section{Results}

All mice were alive at the end of 24-week treatment, and no superficial abnormalities or tumors were found in the abdomen and other parts of the body.

\section{The overall status}

The CHF mice displayed obese phenotype and showed unwieldy. In contrast, CR mice were thin and appeared increased physical activity; they were sensitive to food and foraged actively. Both the SRT and NAM mice had a similar body type to the CR mice after 6-week drug administration.

\section{Energy intake, body weight and visceral fat}

The food intake of the $\mathrm{NC}$ mice remained constant throughout the course of the study, averaging $4.8 \pm 0.02 \mathrm{~g} / \mathrm{d}$ (standard chow, GE $=16.8 \pm 0.07 \mathrm{kcal}$ ). The intake of the CR group was controlled at an average of $3.4 \pm 0.02 \mathrm{~g} / \mathrm{d}$ $(\mathrm{GE}=11.8 \pm 0.06 \mathrm{kcal})$. HF mice consumed $4.7 \pm 0.04 \mathrm{~g} / \mathrm{d}$ (HF diet, $\mathrm{GE}=20.8 \pm 0.17 \mathrm{kcal}$ ) before drug administration (Figure 1A). The caloric consumption was higher in HF group than in the NC group $(P<0.001)$. During SRT1720 treatment, the energy intake of the SRT group gradually decreased in the first two weeks, and then increased in the middle two weeks. However, it decreased again and finally was similar to that of the CR group $(12.1 \pm 0.4 \mathrm{kcal} / \mathrm{d}$ vs. $11.1 \pm 0.1 \mathrm{kcal} / \mathrm{d}, P>0.05)$, lower than that of the $\mathrm{NC}$ group $(16.4 \pm 0.2 \mathrm{kcal} / \mathrm{d}, P<0.001)$ (Figure $1 \mathrm{~B})$. The caloric intake of the NAM group decreased in the first 

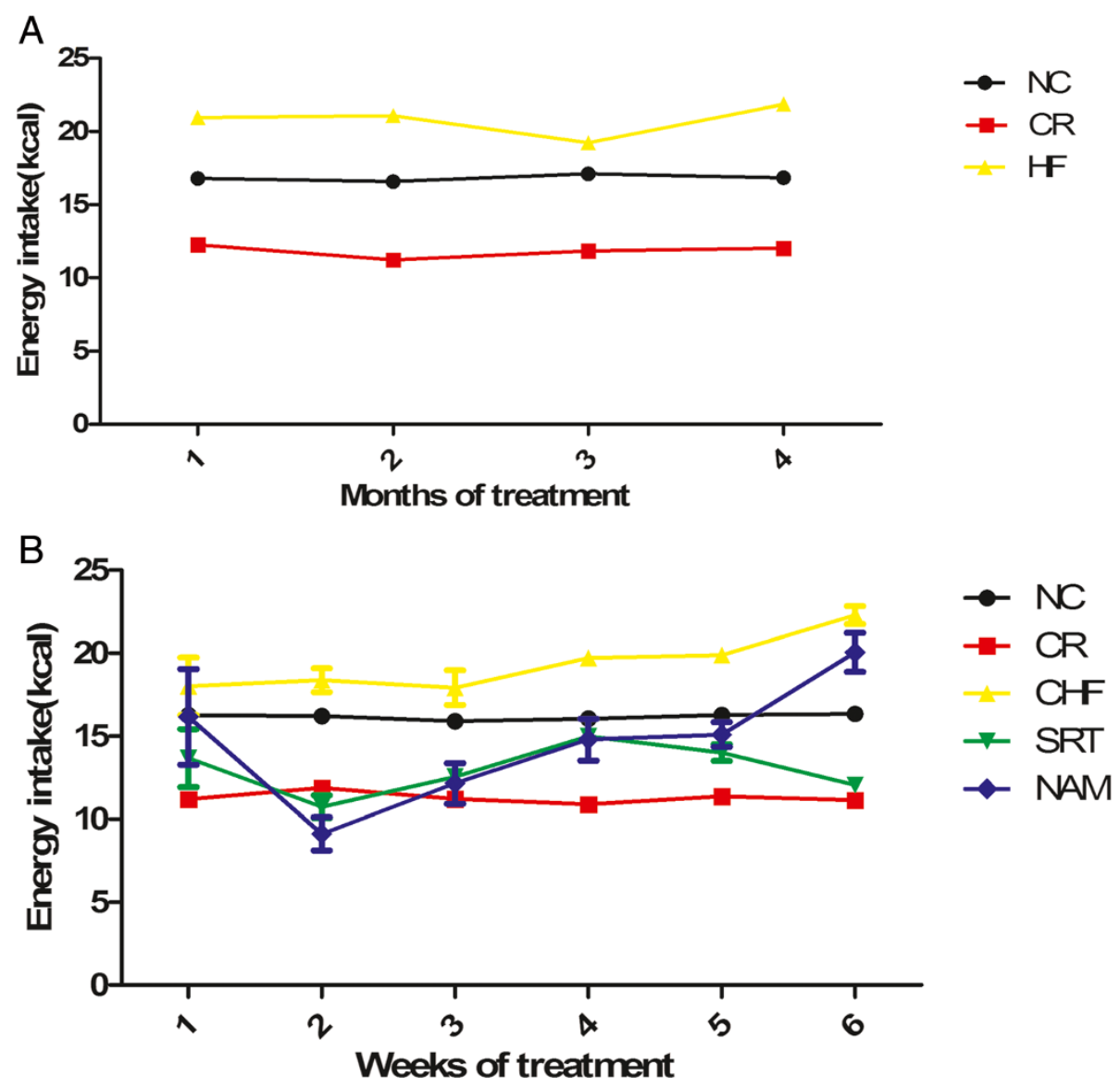

Figure 1 Changes of energy intake among groups. (A) Before drug administration. (B) During drug administration. Food intake was measured every day and the values were represented as means \pm S.E.M.

two weeks, and then gradually increased in the following weeks. At the end of the treatment, it was close to that of the CHF group $(20.1 \pm 1.2 \mathrm{kcal} / \mathrm{d}$ vs. $22.6 \pm 0.5 \mathrm{kcal} / \mathrm{d}$, $P>0.05)$, but higher than that of the NC group $(P<0.001)$ (Figure 1B).

No difference was observed in the body weight of mice among the $\mathrm{NC}, \mathrm{CR}$ and $\mathrm{HF}$ groups before the dietary treatment $(P>0.05)$. The body weight of the $\mathrm{NC}$ mice increased during the 26-week experiment $(35.3 \pm 0.5 \mathrm{~g}$ vs. $40.7 \pm 1.7 \mathrm{~g}, P<0.01$ ), while that of the CR mice decreased slightly and remained relatively stable later $(34.6 \pm 0.7 \mathrm{~g}$ vs. $33.5 \pm 1.6 \mathrm{~g}, P>0.05)$. The body weight of the HF mice significantly increased from $34.9 \pm 0.3 \mathrm{~g}$ to $55.0 \pm 1.0 \mathrm{~g}$ during the four-month dietary treatment $(P<0.001)$ (Figure $2 \mathrm{~A}$ ) and they had $34 \%$ greater body weight than the $\mathrm{NC}$ mice, which were considered as moderate obesity $[30,31]$. Both the SRT group and the NAM group displayed a body weight dropped during the drug administration $(38.7 \pm 1.9$ g vs. $52.1 \pm 1.2 \mathrm{~g}, P<0.05 ; 38.7 \pm 1.5 \mathrm{~g}$ vs. $50.0 \pm 2.1 \mathrm{~g}, P<0.05)$, which were similar to the body weight of the $\mathrm{CR}$ group $(P>0.05)$ (Figure $2 \mathrm{~B})$. However, the body weight of the CHF group remained relatively stable $(56.6 \pm 2.1$ g vs. $54.7 \pm 3.4 \mathrm{~g}, P>0.05)$ (Figure 3 ).

At the end of experiment, the perirenal fat pads were isolated and weighed as the visceral fat. The CHF mice had more visceral fat than the $\mathrm{NC}$ mice, while the visceral fat was less in the CR mice than in the $\mathrm{NC}$ mice. The SRT and NAM mice had similar visceral fat to the NC mice (Table 1).

\section{The ovary weight}

Both the CHF mice and the NAM mice had heavier ovaries and higher ratio of ovary weight to body weight than those of the NC mice. However, the gross ovary weight and ovary ratio of the SRT group were similar to those of the CR group, but less than those of the NC group (Table 1).

\section{Effect of SRT1720 and nicotinamide treatment on estrous cycles}

The estrous cycles of all mice were examined before the treatment and only one of them represented an irregularly 

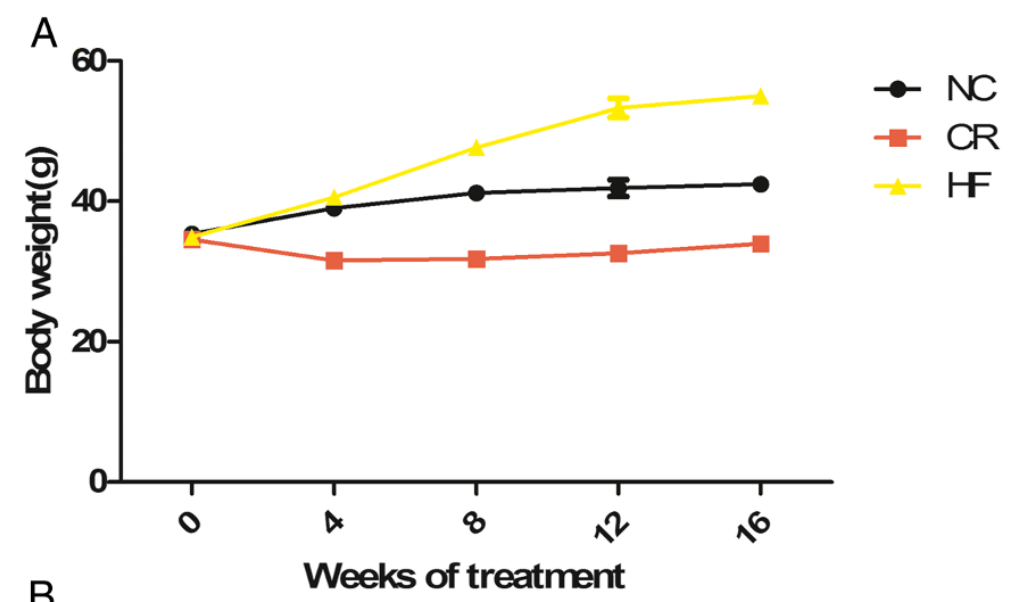

B

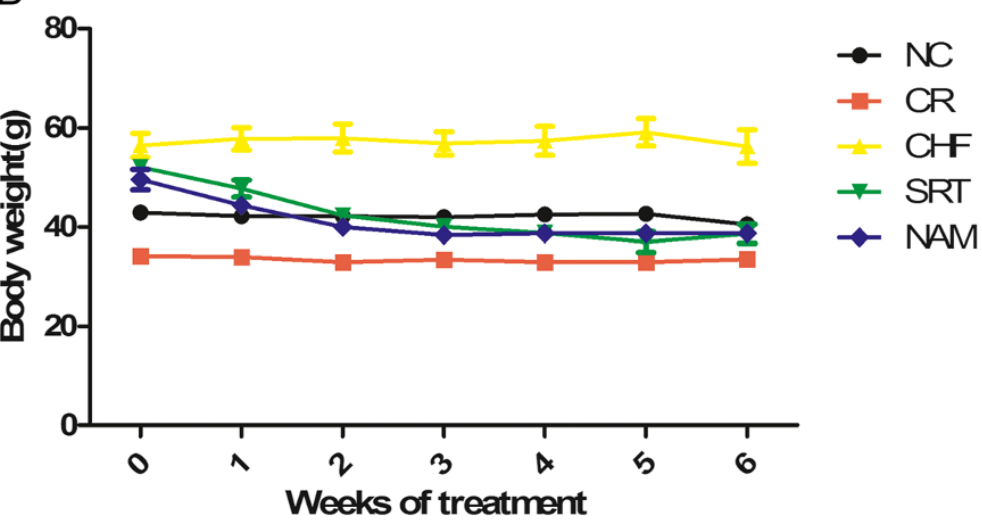

Figure 2 Changes of body weight among groups. (A) Before the drug administration. (B) During the drug administration. The values were represented as means \pm SEM.

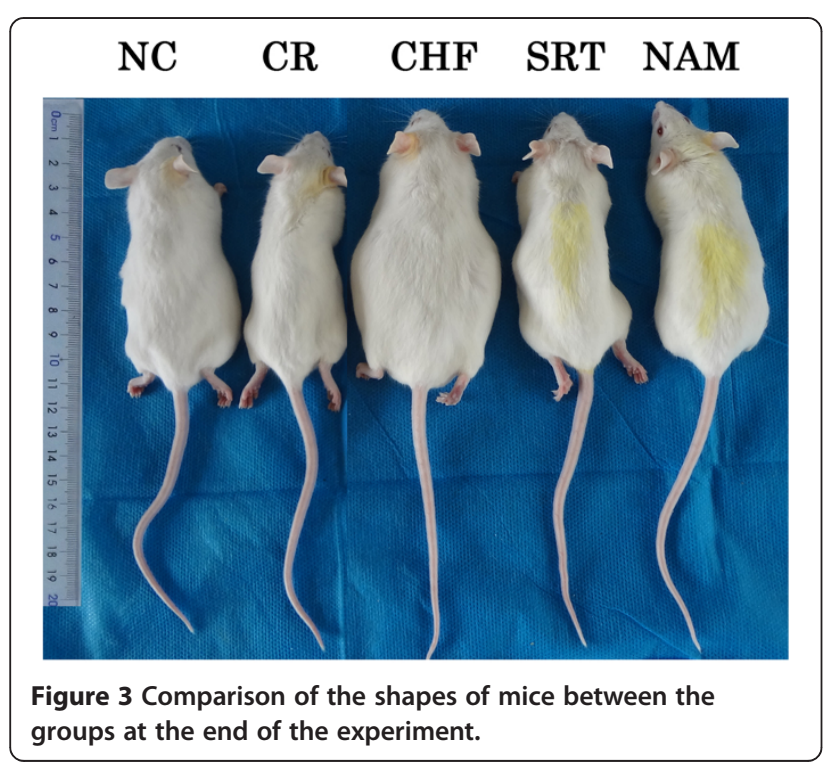

estrous cycle ( $>5$ days). 100\% (20/20) HF mice had exhibited a shortened estrous cycle or continuous estrus phase since the 8 th week of diet treatment. However, after 6-week SRT1720 administration, 50\% (3/6) SRT mice changed the continuous estrus phase to 3, 5 and 6 days, respectively. All the NAM and CHF mice maintained continuous estrus phase during the drug treatment. During the experiment, $87.5 \%$ (7/8) of the CR mice gradually exhibited an extended estrous cycle due to a prolonged diestrus phase and only one CR mouse kept a regular

Table 1 Body weight, ovary weight and visceral fat in all groups at the end of treatment

\begin{tabular}{lllll}
\hline Group & $\begin{array}{l}\text { Body } \\
\text { weight }(\mathbf{g})\end{array}$ & $\begin{array}{l}\text { Ovary } \\
\text { weight }(\mathbf{m g})\end{array}$ & $\begin{array}{l}\text { Ovary/body } \\
\text { weight (\%) }\end{array}$ & Viscal fat (g) \\
\hline NC & $40.7 \pm 1.7$ & $9.1 \pm 0.8$ & 0.022 & $0.25 \pm 0.03$ \\
CR & $33.5 \pm 1.6^{*}$ & $5.9 \pm 0.5^{*}$ & 0.018 & $0.11 \pm 0.03^{*}$ \\
CHF & $56.3 \pm 3.4^{* * *}$ & $18.7 \pm 0.3^{* * *}$ & $0.032^{* *}$ & $1.24 \pm 0.20^{* * *}$ \\
SRT & $38.7 \pm 1.9$ & $5.9 \pm 1.0^{*}$ & 0.015 & $0.32 \pm 0.10$ \\
NAM & $38.7 \pm 1.5$ & $11.7 \pm 1.1$ & $0.031^{*}$ & $0.33 \pm 0.07$ \\
\hline
\end{tabular}

Data are means \pm S.E.M. ${ }^{*} P<0.05,{ }^{* *} P<0.01,{ }^{* * *} P<0.001$ compared with the NC group. 
estrous cycle. Interestingly, two more CR mice and one SRT mice represented regularly again at the end of the study. Meanwhile, $75 \%$ (6/8) NC mice maintained regular estrous cycles until the end (Table 2).

\section{Effect of SRT1720 and nicotinamide treatment on ovarian follicular reserve \\ Comparison of the healthy follicles and atretic follicles among groups}

HE staining results showed that mouse ovaries were mainly consisted of healthy follicles (primordial, primary, secondary and antral follicles), corpora lutea and atretic follicles. The number of healthy follicles in the SRT1720 group was similar to that of the CR group (121.7 \pm 12.6 vs. $125.4 \pm 8.7, P>0.05)$, but more than that of the $\mathrm{NC}$, CHF and NAM group $(121.7 \pm 12.6$ vs. $100.4 \pm 6.5,96.6 \pm 2.2$ and $101.8 \pm 10.3, P<0.05$, respectively). The number of atretic follicles in the SRT1720 group was similar to that of the NC group $(23.2 \pm 2.2$ vs. $28.3 \pm 1.6, P>0.05)$, but less than that of the CHF group and the NAM group $(23.2 \pm 2.2$ vs. $42.2 \pm 2.4,36.3 \pm 2.3, P<0.05)$, while the number of atretic follicles in the $\mathrm{CR}$ group was less than that of the NC group $(16.9 \pm 1.6$ vs. $28.3 \pm 1.6, P<0.001)$ (Figure 4).

\section{Comparison of the number of follicles at different stages among groups}

The mean number and percentage of primordial follicles in the SRT1720 group were more than those of the NC group $(21.5 \pm 1.1$ vs. $13.1 \pm 1.1 ; 11.4 \% \pm 0.7 \%$ vs. $7.7 \% \pm 0.6 \%$, $P<0.001$, respectively), while those of the CHF group and the NAM group were less than those of the NC group $(6.8 \pm 0.3,9.5 \pm 1.1$ vs. $13.1 \pm 1.1, P<0.001, P<0.05$, respectively; $2.7 \% \pm 0.1 \%, 4.5 \% \pm 0.6 \%$ vs. $7.7 \% \pm 0.6 \%$, $P<0.001, P<0.01$, respectively). Although the SRT1720 group had a similar mean number of primordial follicles to the CR group $(21.5 \pm 1.1$ vs. $25.6 \pm 1.0, P>0.05)$, it had less percentage of primordial follicles than the CR group $(11.4 \% \pm 0.7 \%$ vs. $16.2 \% \pm 0.6 \%, P<0.001)$. The mean number and percentage of developing follicles (including primary, secondary and antral follicles) were comparable among groups $(P>0.05)$. The number and percentage of corpora lutea in the SRT1720 group were similar to those of the NC group $(46.2 \pm 4.3$ vs. $40.5 \pm 3.4$

Table 2 Percentage of mice at different stages of the estrous cycle among groups

\begin{tabular}{|c|c|c|c|c|c|}
\hline \multirow{2}{*}{$\begin{array}{l}\text { Age and estrous } \\
\text { cycle stage }\end{array}$} & $N C(n=8)$ & $C R(n=8)$ & CHF $(n=8)$ & SRT $(n=6)$ & NAM $(n=6)$ \\
\hline & $\%$ & $\%$ & $\%$ & $\%$ & $\%$ \\
\hline \multicolumn{6}{|l|}{2 months } \\
\hline Regular cycling & 100 & 100 & 87.5 & 100 & 100 \\
\hline Irregular cycling & 0 & 0 & 12.5 & 0 & 0 \\
\hline \multicolumn{6}{|l|}{3 months } \\
\hline Regular cycling & 100 & 75 & 87.5 & 66.7 & 83.3 \\
\hline Irregular cycling & 0 & 25 & 12.5 & 33.3 & 16.7 \\
\hline \multicolumn{6}{|l|}{4 months } \\
\hline Regular cycling & 100 & 62.5 & 0 & 0 & 0 \\
\hline Irregular cycling & 0 & 37.5 & 100 & 100 & 100 \\
\hline \multicolumn{6}{|l|}{5 months } \\
\hline Regular cycling & 66.7 & 12.5 & 0 & 0 & 0 \\
\hline Irregular cycling & 33.3 & 87.5 & 100 & 100 & 100 \\
\hline \multicolumn{6}{|l|}{6 months } \\
\hline Regular cycling & 75 & 12.5 & 0 & 0 & 0 \\
\hline Irregular cycling & 25 & 87.5 & 100 & 100 & 100 \\
\hline \multicolumn{6}{|l|}{7 months } \\
\hline Regular cycling & 75 & 37.5 & 0 & 0 & 0 \\
\hline Irregular cycling & 25 & 62.5 & 100 & 100 & 100 \\
\hline \multicolumn{6}{|l|}{8 months } \\
\hline Regular cycling & 75 & 37.5 & 0 & 16.7 & 0 \\
\hline Irregular cycling & 25 & 62.5 & 100 & 83.3 & 100 \\
\hline
\end{tabular}

Note: The dietary treatment started at the beginning of 8 weeks ( 2 months) of age and stopped at the end of 32 weeks ( 8 months) of age. The drug administration started at the 26 weeks of age and lasted for 6 weeks. 


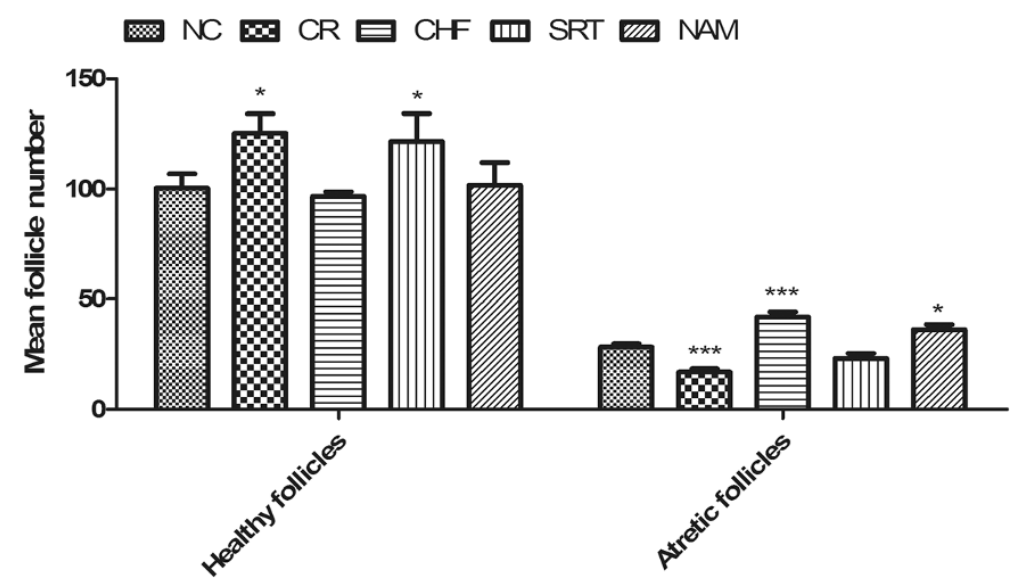

Figure 4 Comparison of the healthy follicles and atretic follicles among groups. Data were presented as mean \pm S.E.M. ${ }^{*} P<0.05$, ${ }^{* *} P<0.01$, ***P $<0.001$ vs. the NC group.

$24.6 \% \pm 2.8 \%$ vs. $24.1 \% \pm 2.1 \%, P>0.05$, respectively), but less than those of the CHF and NAM group (46.2 \pm 4.3 vs. $92.1 \pm 4.9,72.3 \pm 5.0, P<0.001$, respectively; $24.6 \% \pm 2.8 \%$ vs. $37.0 \% \pm 1.8 \%, 34.6 \% \pm 4.4 \% ; P<0.01$, respectively). The CR group had less corpora lutea than the NC group $(17.9 \pm 4.7$ vs. $40.5 \pm 3.4 ; 11.6 \% \pm 1.5 \%$ vs. $24.6 \% \pm 2.8 \%$, $P<0.01$, respectively) (Figure 5).

\section{Western blotting analysis}

To examine the activities of SIRT1/FOXO3a/NRF1SIRT6, mTOR-p70S6K signaling, NFkB and p53 in the ovaries after SRT1720 and nicotinamide treatment, the protein expression of SIRT1, SIRT6, FOXO3a, NRF-1, mTORC1, p-mTOR, p-p70S6K, NFkB and p53 was measured by Western blotting. The result demonstrated that the level of SIRT1, SIRT6, FOXO3a and NRF-1 proteins significantly increased in the ovaries of the SRT and CR mice, whereas that of mTORC1, p-mTOR, p-p70S6K, NF-kB and p53 decreased compared to the NC mice. Contrarily, the CHF and NAM mice displayed a significant increase of mTORC1, p-mTOR, p-p70S6K, NFkB and p53, and a significant decrease of SIRT1, SIRT6, FOXO3a and NRF-1 proteins compared to the NC and SRT mice (Figure 6).

\section{Discussion}

The epidemic of obesity is now recognized as one of the most important public health problems facing the world today and its impact on fertility is significant. As the prevalence of obesity is increasing, the number of women in the reproductive age who are becoming overweight and obese has the same trend. Obesity impacts at least $30 \%$ of reproductive aged women [32]. Weight-loss programs can improve fertility, hormones, ovulation in obese female [33]. CR is an effective way to lose weight and useful for prolonging the ovarian lifespan. Weight loss provides many benefits, but changing eating behavior and maintenance of ideal weight are difficult and hard to achieve $[34,35]$. Therefore, greater efforts are being devoted to understanding the mechanisms of CR-mediated regulation of ovarian follicle development so that it can provide new insight into extending ovarian lifespan and also into the potential therapeutic targets for obese females.

\section{High-fat diet induced obesity accelerated the ovarian follicle development and rate of follicle loss}

In the present study, our data showed that obesity was effectively induced since adult (8 weeks old) in mice by ad libitum feeding of a high fat diet, for the CHF mice had greater body weight and visceral fat at the end of the study. Moreover, the CHF mice had less number and percentage of primordial follicles, and a greater number of corpora lutea and atretic follicles, suggesting that the high-fat diet induced obesity may accelerate the rate of follicle loss at least in three ways: i) stimulating the activation of primordial follicles; ii) promoting the development and maturity of ovarian follicles; iii) promoting follicle apoptosis. These results were coincident with our previous findings [10].

SIRT 1 signaling was involved in the regulation of ovarian follicle development

Mammalian SIRT1, the ortholog of yeast Sir2, is a class III histone deacetylase (HDAC) whose activation is dependent on nicotinamide adenine dinucleotide in the nucleus $[36,37]$. It not only deacetylates histones, but also has a wide range of non-histone sustrates, such as the forkhead box class $\mathrm{O}$ (FOXO) family, p53 and nuclear factor $\mathrm{kB}$ (NFkB), etc. [38-40]. Accumulated evidence has revealed that SIRT1 is crucial for caloric restriction-induced longevity [41-43], and SIRT1 genetic variation is related to obesity 

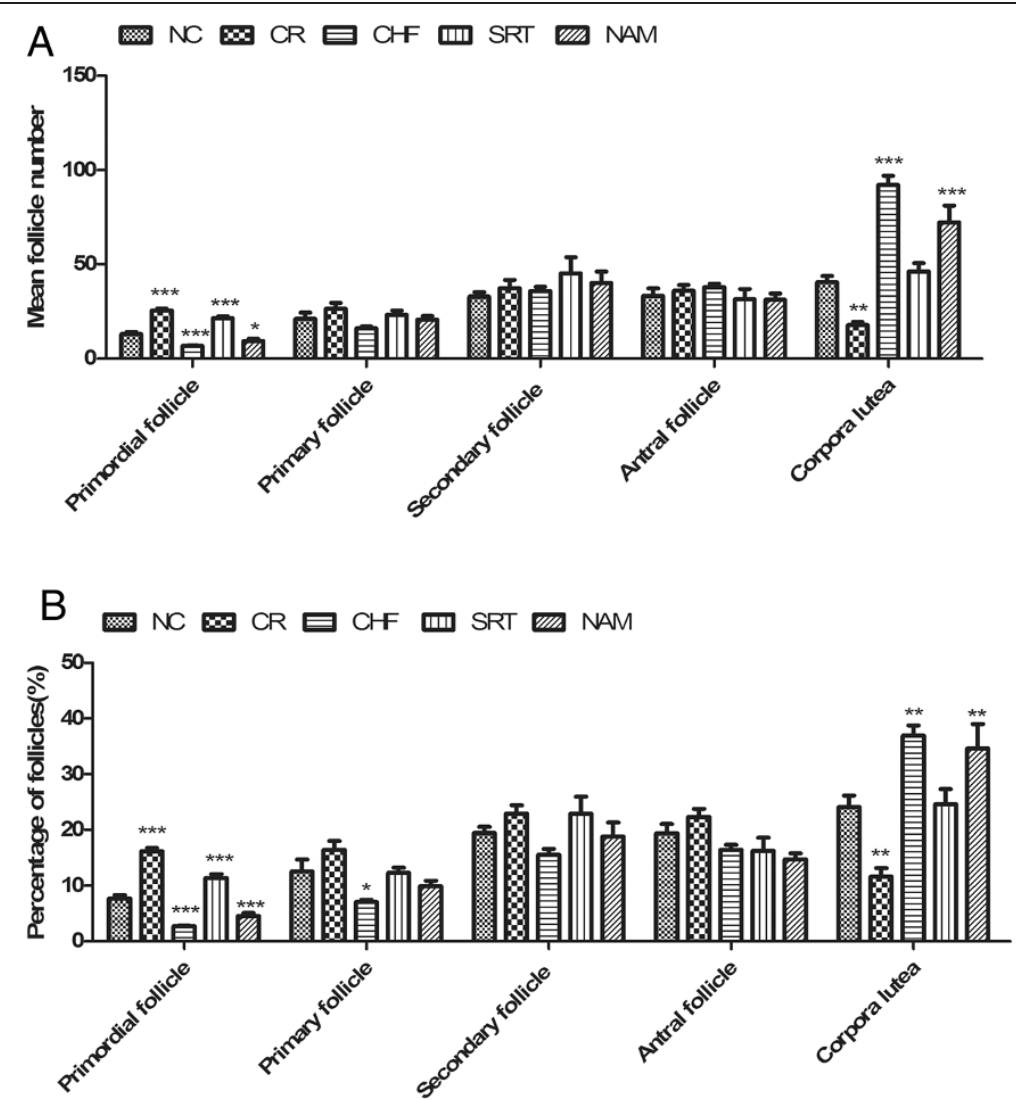

Figure 5 Comparison of ovarian follicles at each stage among groups. (A) The mean number of ovarian follicles at each stage among groups. (B) Percentage of ovarian follicles at each stage among groups. Data were presented as mean \pm S.E.M. ${ }^{*} P<0.05,{ }^{*} P<0.01,{ }^{* *} P<0.001$ vs. the NC group.

[44], suggesting that SIRT1 is a key regulator of wholebody energy balance. SIRT1 also plays a role in reproductive biology. SIRT 1 transgenic mice showed phenotypes resembling $\mathrm{CR}$ and displayed prolonged lifespan, inhibited ovarian follicular development and delayed sexual maturity [45], whereas both male and female sirt1null mice were barren [46-48]. FOXO3a is known as an important substrate of SIRT1. Mice with deletion of FOXO3a gene have been shown to have abnormal ovarian follicular development with early degeneration of oocytes, resulting in age-dependent infertility [49], whereas sexual maturity was delayed and follicle development was inhibited in oocyte specific FOXO3a transgenic mice [50]. Our previous study demonstrated that CR improved the follicle reserve and extended ovarian lifespan with increasing expression of SIRT1 and SIRT6 [51]. On the contrary, the level of SIRT1 and SIRT6 expression in the ovaries decreased in obese rats [10]. Kim et al. recently reported SIRT1 forms a complex with FOXO3a and NRF1 on the SIRT6 promoter to positively regulated expression of SIRT6 [52]. Our study also suggested that SIRT1/ FOXO3a/NRF1- SIRT6 signaling may be involved in CR extending ovarian lifespan mechanisms [10].
Both SIRT 1 transgenosis and activators of SIRT 1 can mimic CR effect. However, it has remained elusive whether SIRT1 signaling plays a role in the development of ovarian follicles. Thus, we used SRT1720, the specific activator of SIRT1, to investigate its effect on the follicle development of the high-fat diet induced obesity mice. Our results showed that SRT1720 treatment caused an increase in the number and percentage of primordial follicles, which was comparable to CR treatment, suggesting that SRT1720 may inhibit the activation of primordial follicles like CR. Although the numbers of secondary and antral follicles were not significantly affected, the number and percentage of corpora lutea were decreased by the SRT1720 and CR treatment, suggesting that SRT1720 and $\mathrm{CR}$ may suppress follicle maturation. This may explain that the SRT1720-treated and CR ovaries were smaller than those of the control. Moreover, both the number and percentage of atretic follicles were significantly decreased by SRT1720, suggesting that SRT1720 may inhibit follicular atresia. Nicotinamide, a form of vitamin B3, is a product of Sir2-catalyzed deacetylation [53]. It has been clearly demonstrated that nicotinamide can inhibit Sir2 enzymes and down-regulate the expression of SIRT1 [54]. In the 


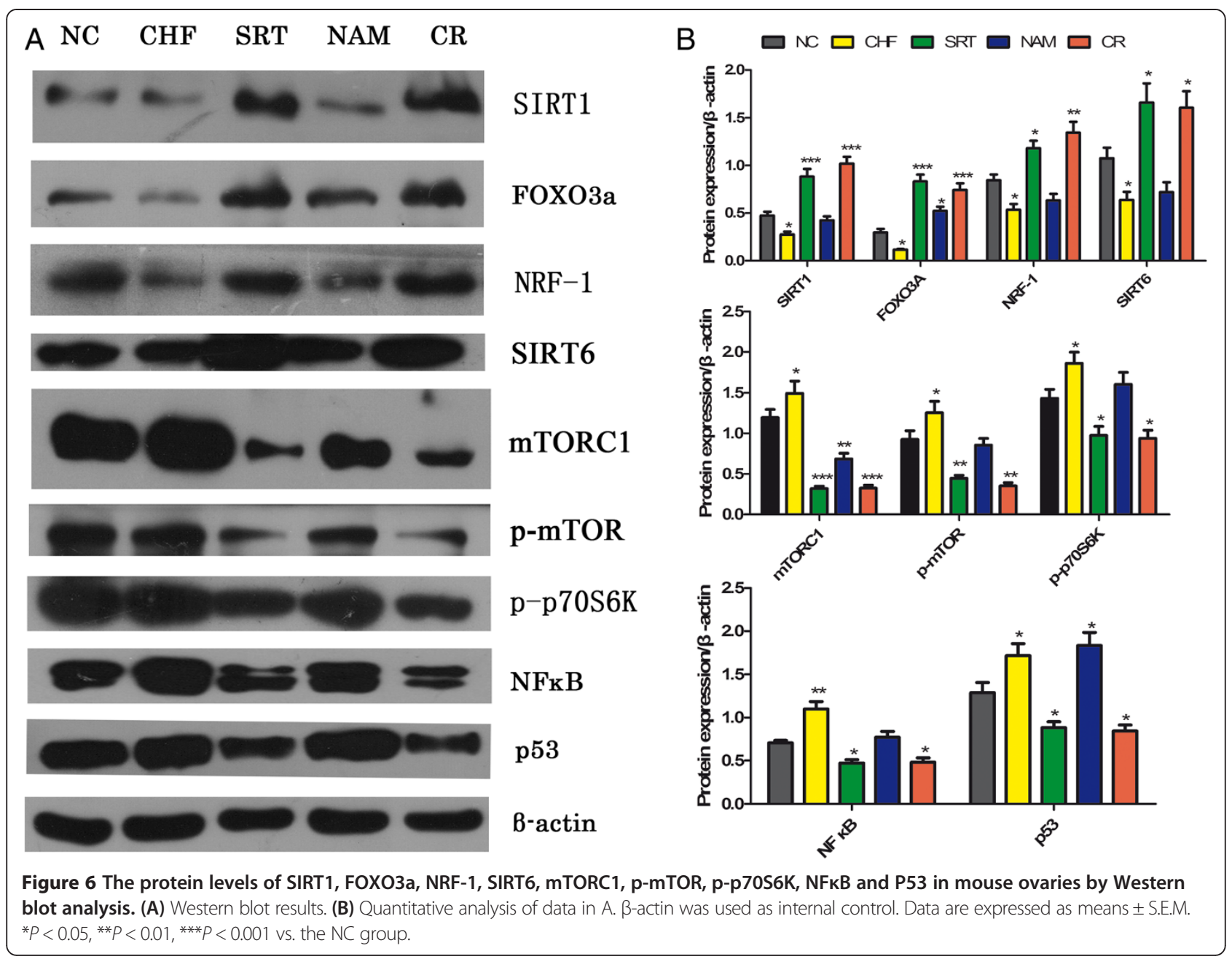

present study, the nicotinamide-treated mice had distinct features to the SRT or CR mice, their ovary weight, total number of follicles and mean number of follicles at different stages were comparable to that of the $\mathrm{NC}$ and $\mathrm{CHF}$ mice, suggesting that nicotinamide attenuated the effect of SRT1720. These results also suggest that SIRT1 signaling may play an important role in the mechanism of CR extending ovarian lifespan.

\section{SRT1720 treatment extended estrous cycle}

It has been established that female reproductive aging is closely associated with a decreased ovarian follicle reserve and gradual loss in regular estrous cyclicity at middle age $[55,56]$ Hence, we examined the status of estrous cycle in all groups. We found that the CR mice gradually displayed an extended estrous cycle due to a prolonged diestrus phase, while most HF mice exhibited a shortened estrous cycle or continuous estrus phase before drug treatment. After treated with SRT1720, 3 of the 6 SRT mice changed the continuous estrus phase to 3,5 and 6 days, respectively. We supposed that the extended estrous cycle of the CR and SRT mice resulted from insufficient estrogen secreted by fewer mature follicles. This is in agreement with our follicle count results.

\section{SRT1720 treatment enhanced SIRT 1 signaling and attenuated mTOR signaling}

mTOR (mammalian target of rapamycin,also known as Frap1 in mice and other mammals), a ubiquitous, evolutionarily conserved serine/threonine kinase, acts as a central regulator of eukaryotic growth and cell division in response to nutrient and growth factor cues. mTOR generates two distinct complexes: rapamycin sensitive mTOR complex 1 (mTORC1) and rapamycin insensitive mTORC2. Previous studies reported that mTORC1S6K1-rpS6 signaling may be involved in the activation of mammalian primordial follicles [57-59] and was negatively regulated by SIRT1 [60].

With mammalian models of CR in our studies, we found that CR significantly enhanced the reserve of follicle pool by suppressing the activation of primordial follicles as well as decreased protein expression of mTOR 
and pS6K, suggesting that $\mathrm{CR}$ could inhibited mTORS6K signaling [10]. Interestingly, our results of the present study also showed that SRT1720 had similar effects with CR, in which SRT1720 not only enhanced the reserve of follicle pool, but also down-regulated mTOR signaling, suggesting that mTOR signaling may be negatively regulated by SIRT1 signaling. We found, moreover, in the present study that SRT1720 induced a decrease of energy intake by $\sim 33.4 \%$ (about $66.6 \%$ energy intake of the CHF mice), meaning that the SRT1720-treated mice were in a CR condition. Consistently, the body weight of SRT1720-treated mice was significantly less than that of the CHF mice, although they ate the same food as the CHF mice. These data also suggest that the effect of CR is realized through the activation of SIRT1. Taking together, we speculate that SRT1720 may enhance the reserve of follicle pool by directly up-regulating SIRT1 signaling and thus down-regulating mTOR expression.

\section{SRT1720 treatment attenuated NFKB signaling}

Physiological events within the ovary, including ovulation and corpus luteum formation and regression, have been described as controlled inflammatory events [61].It is now established that obesity causes a state of chronic low-grade inflammation. Compared to healthy lean individuals, overweight and obese individuals have higher pro-inflammatory cytokines, such as nuclear factor $\mathrm{kB}$ $[62,63]$. It may partly explain why the CHF mice had more corpus lutea and a higher expression of NFkB. $\mathrm{NFKB}$ is a downstream of SIRT1 and it activates several other pro-inflammatory cytokines (IL- 6 , TNF- $\alpha$, IL-1 $\beta$ ) [64]. A recent study reported that the specific SIRT1 activator SRT1720 exerted anti-inflammatory effects [65]. Consistently, our present study also found that SRT1720treated mice, as well as the CR mice, displayed significantly decreased level of NFkB compared to the CHF mice, suggesting that SIRT1 may play an important role in the anti-inflammatory effect of $\mathrm{CR}$ and further contribute to ovarian follicle development.

\section{SRT1720 treatment inhibited p53 protein expression}

P53, a tumor suppressor gene regulated by SIRT1mediated deacetylation, is a positive regulator of apoptosis in its native form (wild-type). The expression of p53 protein in the apoptotic granulosa cells of atretic follicles suggests its possible role in atresia [66]. A study also showed that p53 played an important role in the regulation and selection of oocytes at checkpoints, such that oocytes that would otherwise be lost may persist when p53 was absent or reduced [67]. These data suggest that p53 may be associated with follicle atresia. SIRT1 regulates p53 acetylation and p53-dependent apoptosis [68]. Therefore, we examined the effect of CR and SRT1720 on p53 protein expression in the mouse ovary. The results showed that both CR and SRT1720 could inhibit p53 protein expression in the ovaries, which was probably due to the activation of SIRT1.

\section{Conclusions}

Our present study suggests that SRT1720 treatment may promote the ovarian lifespan of HF diet-induced obesity female mice by suppressing the activation of primordial follicles, the follicle maturation and atresia via activating SIRT1 signaling and suppressing mTOR signaling. It may also reduce the inflammatory reaction via modulating $\mathrm{NF \kappa B}$ signaling. We believe that a better understanding of the interrelationship between SIRT1 and mTOR signaling will promote the development of new pharmacological insights to treat metabolic diseases associated with obesity.

\section{Abbreviations}

CR: Calorie restriction; CHF: Control high fat; FOXO3a: Forkhead box group $\mathrm{O}$ 3a; HF: High fat; H\&E: Hematoxylin and eosin; mTOR: Mammalian target of rapamycin; mTORC: Mammalian target of rapamycin complex; NC: Normal control; NAM: Nicotinamide; NRF-1: Nuclear respiratory factor 1; NFKB: Nuclear factor KB; PAGE: Polyacry1 amide gelelectrophoresis; PBS: Phosphate buffer solution; p-p70S6K: Phosphor-p70 ribosomal protein S6 kinases; p-mTOR: Phosphor- mammalian target of rapamycin; PMSF: Phenylmethanesulfonyl fluoride; RIPA: Radio-immunoprecipitation assay; SIRT1: Silent information regulator 2 related enzyme 1; SIRT6: Silent information regulator 2 related enzyme 6; SDS: Sodium dodecyl sulfate; S.E.M: Standard error of mean; SPSS: Statistical package for the social sciences; TBST: Tris-buffered-saline with tween 20.

\section{Competing interests}

The authors declare that they have no competing interests.

\section{Authors' contributions}

XLZ performed histological and Western blotting analysis of mice ovaries, found the results and wrote the manuscript. JJX helped in planning, supervised the work. YHN helped in taking care of mice and taking down data. XCC: participated in the design of the study. HXZ helped in taking care of mice and taking down data. XMZ participated in the design of the study. WJL: participated in the design of the study. YCF participated in the design of the study, supervised the work and corrected the final version of manuscript. LLL helped in planning, supervised the work and approved a final version of the manuscript. All authors read and approved the final manuscript.

\section{Acknowledgment}

This work was supported by the National Natural Science Foundation of China (nos. 81270670).

\section{Author details}

'Department of Gynaecology and Obstetrics of the First Affiliated Hospital, Shantou University Medical College, Shantou, Guangdong Province 515041, People's Republic of China. ${ }^{2}$ Laboratory of Cell Senescence, Shantou University Medical College, 22 Xin Ling Rd, Jinping District, Shantou, Guangdong Province 515041, People's Republic of China. ${ }^{3}$ Department of Gynaecology and Obstetrics of Huizhou Municipal Central Hospital, Huizhou, Guangdong Province 516001, People's Republic of China.

Received: 19 July 2014 Accepted: 11 October 2014

Received: 19 July 2014 Accepted: 11 Octob

\section{References}

1. Marie N, Tom F, Margaret R, Blake T, Nicholas G, Christopher M, Erin CM, Stan B, Cristiana A, Semaw FA, Jerry PA: Global, regional, and national prevalence of overweight and obesity in children and adults during 1980-2013: a systematic analysis for the Global Burden of Disease Study 2013. Lancet 2014, 384(9945):766-81. 
2. Mayes JS, Watson GH: Direct effects of sex steroid hormones on adipose tissues and obesity. Obes Rev 2004, 5(2):197-216.

3. Balasubramanian P, Jagannathan L, Mahaley RE, Subramanian M, Gilbreath ET, Mohankumar PS, Mohankumar SM: High fat diet affects reproductive functions in female diet-induced obese and dietary resistant rats. J Neuroendocrinol 2012, 24(5):748-755.

4. Kirschner MA, Schneider G, Ertel NH, Worton E: Obesity, androgens, oestrogens, and cancer risk. Cancer Res 1982, 42:3281-3285.

5. Pasquali R, Casimirri F: The impact of obesity on hyperandrogenism and polycystic ovary syndrome in premenopausal women. Clin Endocrinol (Oxf) 1993, 39(1):16.

6. Metwally M, Cutting R, Tipton A, Skull J, Ledger WL, Li TC: Effect of increased body mass index on oocyte and embryo quality in IVF patients. Reprod Biomed Online 2007, 15(5):532-538.

7. Natalia I, Andrey YA, Lucilla P, Judith JE, Tom PF, Michael RD, Josie MC: Maternal diet-induced obesity alters mitochondrial activity and redox status in mouse oocytes and zygotes. PLoS One 2010, 5:e10074.

8. Jungheim ES, Schoeller EL, Marquard KL, Louden ED, Schaffer JE, Moley KH: Diet-induced obesity model: abnormal oocytes and persistent growth abnormalities in the offspring. Endocrinology 2010, 151:4039-4046.

9. Robker RL, Wu LL, Yang X: Inflammatory pathways linking obesity and ovarian dysfunction. J Reprod Immunol 2011, 88:142-148.

10. Wang $N$, Luo LL, Xu JJ, Xu MY, Zhang XM, Zhou XL, Liu WJ, Fu YC: Obesity accelerates ovarian follicle development and follicle loss in rats. Metabolism 2014, 63(1):94-103.

11. Gregory FE: Role of growth factors in ovary organogenesis. J Soc Gy-necol Investig 2001, 8:S13-S16.

12. Coulam CB, Adamson SC, Annegers JF, Annegers JF: Incidence of premature ovarian failure. Obstet Gynecol 1986, 67:604-606.

13. Luborsky JL, Meyer P, Sowers MF, Gold EB, Santoro N: Premature menopause in a multi-ethnic population study of the menopause transition. Hum Reprod 2003, 18:199-206.

14. Pandey S, Bhattacharya S: Impact of obesity on gyneclogy. Womens Health 2010, 6(1):107.

15. Wing RR, Lang W, Wadden TA, Safford M, Knowler WC, Bertoni AG, Hill JO, Brancati FL, Peters A, Wagenknecht L: Benefits of modest weight loss in improving cardiovascular risk factors in overweight and obese individuals with type 2 diabetes. Diabetes Care 2011, 34:1481-1486.

16. ACOG: Committee on practice bulletins-gynecology: ACOG practice bulletin no 108: polycystic ovary syndrome. Obstet Gynecol 2009, 114(4):936-949.

17. Timmers S, Konings E, Bilet L, Houtkooper RH, van de Weijer T, Goossens GH, Hoeks J, van der Krieken S, Ryu D, Kersten S, Moonen-Kornips E, Hesselink MK, Kunz I, Schrauwen-Hinderling VB, Blaak EE, Auwerx J, Schrauwen P: Calorie restriction-like effects of 30 days of resveratrol supplementation on energy metabolism and metabolic profile in obese humans. Cell Metab 2011, 14(5):612-622.

18. Pearson K, Baur JA, Lewis KN, Peshkin L, Price NL, Labinskyy N, Swindell WR, Kamara D, Minor RK, Perez E, Jamieson HA, Zhang Y, Dunn SR, Sharma K, Pleshko N, Woollett LA, Csiszar A, Ikeno Y, Le Couteur D, Elliott PJ, Becker KG Navas P, Ingram DK, Wolf NS, Ungvari Z, Sinclair DA, de Cabo R: Resveratrol delays age-related deterioration and mimics transcriptional aspects of dietary restriction without extending life span. Cell Metab 2008, 8(2):157-168.

19. Das M, Das DK: Resveratrol and cardiovascular health. Mol Aspects Med 2010, 31(6):503-512

20. Szkudelska K, Szkudelski T: Resveratrol, obesity and diabetes. Eur J Pharmacol 2010, 635:1-8.

21. Chen ZG, Luo LL, Xu JJ, Zhuang XL, Kong XX, Fu YC: Effects of plant polyphenols on ovarian follicular reserve in aging rats. Biochem Cell Biol 2010, 88(4):737-745

22. Liu M, Yin Y, Ye X, Zeng M, Zhao Q, Keefe DL, Liu L: Resveratrol protects against age-associated infertility in mice. Hum Reprod 2013, 28(3):707-717.

23. Beher D, Wu J, Cumine S, Kim KW, Lu SC, Atangan L, Wang M: Resveratrol is not a direct activator of SIRT1 enzyme activity. Chem Biol Drug Des 2009, 74:619-624.

24. Smith JJ, Kenney RD, Gagne DJ, Frushour BP, Ladd W, Galonek HL, Israelian K, Song J, Razvadauskaite G, Lynch AV, Carney DP, Johnson RJ, Lavu S, Iffland A, Elliott PJ, Lambert PD, Elliston KO, Jirousek MR, Milne JC, Boss O: Small molecule activators of SIRT1 replicate signaling pathways triggered by calorie restriction in vivo. BMC Syst Biol 2009, 3:31.

25. Milne JC, Lambert PD, Schenk S, Carney DP, Smith JJ, Gagne DJ, Jin L, Boss O, Perni RB, Vu CB, Bemis JE, Xie R, Disch JS, Ng PY, Nunes JJ, Lynch AV, Yang H,
Galonek H, Israelian K, Choy W, Iffland A, Lavu S, Medvedik O, Sinclair DA, Olefsky JM, Jirousek MR, Elliott PJ, Westphal CH: Small molecule activators of SIRT1 as therapeutics for the treatment of type 2 diabetes. Nature 2007, 450(7170):712-716.

26. Hiney JK, Srivastava V, Nyberg CL, Ojeda SR, Dees WL: Insulin-like growth factor I of peripheral origin acts centrally to accelerate the initiation of female puberty. Endocrinology 1996, 137:3717-3728.

27. Schedin P, Mitrenga T, Kaeck M: Estrous cycle regulation of mammary epithe-lial cell proliferation, differentiation, and death in the SpragueDawley rat:a model for investigating the role of estrous cycling in mammary carcinogenesis. J Mammary Gland Biol Neoplasia 2000, 5(2):211-225.

28. Luo LL, Huang J, Fu YC, Xu JJ, Qian YS: Effects of tea polyphenols on ovarian development in rats. J Endocrinol Invest 2008, 31:1110-1118.

29. Juliani CC, Silva-Zacarin EC, Santos DC, Boer PA: Effects of atrazine on female Wistar rats: morphological alterations in ovarian follicles and immunocytochemical labeling of $90 \mathrm{kDa}$ heat shock protein. Micron 2008, 39:607-616.

30. Harrold JA, Williams G, Widdowson PS: Early leptin response to a palatable diet predicts dietary obesity in rats: key role of melanocortin-4 receptors in the ventromedial hypothalamic nucleus. J Neurochem 2000, 74:1224-1228.

31. Woods SC, Seeley RJ, Rushing PA, D'Alessio D, Tso P: A controlled high-fat diet induces an obese syndrome in rats. J Nutr 2003, 133:1081-1087.

32. Nelson SM, Fleming R: Obesity and reproduction: impact and interventions. Curr Opin Obstet Gynecol 2007, 19:384-389.

33. Clark AM, Ledger W, Galletly C, Tomlinson L, Blaney F, Wang X, Norman RJ Weight loss results in significant improvement in pregnancy and ovulation rates in anovulatory obese women. Hum Reprod 1995, 10:2705-2712.

34. Freund $\mathrm{AM}$, Hennecke M: Changing eating behaviour vs. losing weight: the role of goal focus for weight loss in overweight women. Psychol Health 2012, 27:25-42.

35. Wing RR, Hill JO: Successful weight loss maintenance. Annu Rev Nutr 2001, 21:323-341.

36. Imai S, Armstrong CM, Kaeberlein M, Guarente L: Transcriptional silencing and longevity protein Sir2 is an NAD-dependent histone deacetylase. Nature 2000, 403:795-800.

37. Smith JS, Brachmann CB, Celic I, Kenna MA, Muhammad S, Starai VJ, Avalos J L, Escalante-Semerena JC, Grubmeyer C, Wolberger C, Boeke JD: A phylogenetically conserved NAD + -dependent protein deacetylase activity in the Sir2 protein family. Proc Natl Acad Sci USA 2000, 97:6658-6663.

38. Huang H, Tindall DJ: Dynamic FoxO transcription factors. J Cell Sci 2007, 120:2479-2487.

39. Salminen A, Kauppinen A, Suuronen T, Kaarniranta K: SIRT1 longevity factor suppresses NFkappaB-driven immune responses: regulation of aging via NFkappaB acetylation? Bioessays 2008, 30:939-942

40. van Leeuwen I, Lain S: Sirtuins and p53. Adv Cancer Res 2009, 102:171-195.

41. Kaeberlein M, McVey M, Guarente L: The SIR2/3/4 complex and SIR2 alone promote longevity in Saccharomyces cerevisiae by two different mechanisms. Genes Dev 1999, 13:2570-2580.

42. Tissenbaum HA, Guarente L: Increased dosage of a sir-2 gene extends lifespan in Caenorhabditis elegans. Nature 2001, 410:227-230.

43. Rogina B, Helfand SL: Sir2 mediates longevity in the fly through a pathway related to calorie restriction. Proc Natl Acad Sci U S A 2004, 101:15998-16003.

44. Zillikens MC, van Meurs JB, Rivadeneira F, Amin N, Hofman A, Oostra BA, Sijbrands EJ, Witteman JC, Pols HA, van Duijn CM, Uitterlinden AG: SIRT1 genetic variation is related to $\mathrm{BMI}$ and risk of obesity. Diabetes 2009, 58:2828-2834

45. Bordone L, Cohen D, Robinson A, Motta MC, van Veen E, Czopik A, Steele AD, Crowe H, Marmor S, Luo J, Gu W, Guarente L: SIRT1 transgenic mice show phenotypes resembling calorie restriction. Aging Cell 2007, 6(6):759-767.

46. McBurney MW, Yang X, Jardine K, Hixon M, Boekelheide K, Webb JR, Lansdorp PM, Lemieux M: The mammalian SIR2 protein has a role in embryogenesis and gametogenesis. Mol Cell Biol 2003, 23(1):38-54.

47. Seifert EL, Caron AZ, Morin K, Coulombe J, He XH, Jardine K, Dewar-Darch D,

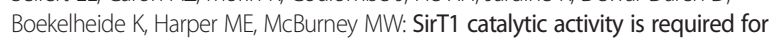
male fertility and metabolic homeostasis in mice. FASEB J 2012, 26(2):555-566.

48. Coussens M, Maresh JG, Yanagimachi R, Maeda G, Allsopp R: Sirt1 deficiency attenuates spermatogenesis and germ cell function. PLoS One 2008, 3(2):e1571.

49. Hosaka T, Biggs WH 3rd, Tieu D, Boyer AD, Varki NM, Cavenee WK, Arden KC: Disruption of forkhead transcription factor (FOXO) family members in mice 
reveals their functional diversification. Proc Natl Acad Sci USA 2004, 101:2975-2980.

50. Pelosi E, Omari S, Michel M, Ding J, Amano T, Forabosco A, Schlessinger D, Ottolenghi C: Constitutively active Foxo3 in oocytes preserves ovarian reserve in mice. Nat Commun 2013, 4:1843.

51. Luo LL, Chen XC, Fu YC, Xu JJ, Li L, Lin XH, Xiang YF, Zhang XM: The effects of caloric restriction and a high-fat diet on ovarian lifespan and the expression of SIRT1 and SIRT6 proteins in rats. Aging Clin Exp Res 2012, 24(2):125-133.

52. Kim HS, Xiao C, Wang RH, Lahusen $T$, Xu X, Vassilopoulos A, Vazquez-Ortiz G, Jeong WI, Park O, Ki SH, Gao B, Deng CX: Hepatic-specific disruption of SIRT6 in mice results in fatty liver formation due to enhanced glycolysis and triglyceride synthesis. Cell Metab 2010, 12(3):224-236.

53. Dietrich: Regulation of nicotinamide metabolism. Am J Clin Nutr 1971, 24:800-804.

54. Bitterman KJ, Anderson RM, Cohen HY, Latorre-Esteves M, Sinclair DA: Inhibition of silencing and accelerated aging by nicotinamide, a putative negative regulator of yeast Sir2 and human SIRT1. J Biol Chem 2002, 277:45099-45107.

55. Anzalone CR, Hong LS, Lu JK, LaPolt PS: Influences of age and ovarian follicular reserve on estrous cycle patterns, ovulation, and hormone secretion in the Long-Evans rat. Biol Reprod 2001, 64(4):1056-1062.

56. Lu JK, Anzalone CR, LaPolt PS: Relation of neuroendocrine function to reproductive decline during aging in the female rat. Neurobiol Aging 1994, 15(4):541-544.

57. Adhikari D, Liu K: Molecular mechanisms underlying the activation of mamma-lian primordial follicles. Endocr Rev 2009, 30:438-464.

58. Adhikari D, Flohr G, Gorre N, Shen Y, Yang H, Lundin E, Lan Z, Gambello MJ, Liu K: Disruption of Tsc2 in oocytes leads to overactivation of the entire pool of primordial follicles. Mol Hum Reprod 2010, 15:765-770.

59. Zhang XM, Li L, Xu JJ, Wang N, Liu WJ, Lin XH, Fu YC, Luo LL: Rapamycin preserves the follicle pool reserve and prolongs the ovarian lifespan of female rats via modulating mTOR activation and sirtuin expression. Gene 2013, 523(1):82-87.

60. Ghosh HS, McBurney M, Robbins PD: SIRT1 negatively regulates the mammalian target of rapamycin. PLOS One 2010, 5:e9199.

61. Espey LL: Ovulation as an inflammatory reaction-a hypothesis. Biol Reprod 1980, 22:73-106

62. Patel C, Ghanim H, Ravishankar S, Sia CL, Viswanathan P, Mohanty P, Dandona P: Prolonged reactive oxygen species generation and nuclear factor-kappaB activation after a high-fat, high-carbohydrate meal in the obese. J Clin Endocrinol Metab 2007, 92:4476-4479.

63. Manning PJ, Sutherland WH, McGrath MM, de Jong SA, Walker RJ, Williams MJ: Postprandial cytokine concentrations and meal composition in obese and lean women. Obesity (Silver Spring) 2008, 16:2046-2052.

64. Nishikori M: Classical and alternative NF-kB tivation pathwaysand their roles in lymphoid malignancies. J Clin Exp Hematop 2005, 45:15-24.

65. Ichikawa T, Hayashi R, Suzuki K, Imanishi S, Kambara K, Okazawa S, Inomata M, Yamada T, Yamazaki Y, Koshimizu Y, Miwa T, Matsui S, Usui I, Urakaze M, Matsuya Y, Sasahara M, Tobe K: Sirtuin 1 activator SRT1720 suppresses inflammation in an ovalbumin-induced mouse model of asthma. Respirology 2013, 18:332-339.

66. Kim JM, Yoon YD, Tsang BK: Involvement of the Fas/Fas ligand system in p53-mediated granulosa cell apoptosis during follicular development and atresia. Endocrinology 2009, 140:2307-2317

67. Ghafari F, Pelengaris S, Walters E, Hartshorne GM: Influence of p53 and genetic background on prenatal oogenesis and oocyte attrition in mice. Hum Reprod 2009, 24:1460-1472.

68. Cheng HL, Mostoslavsky R, Saito S, Manis JP, Gu Y, Patel P, Bronson R, Appella E, Alt FW, Chua KF: Developmental defects and p53 hyperacetylation in Sir2 homolog (Sirt1)-deficient mice. Proc Natl Acad Sci USA 2003, 100:10794-10799.

doi:10.1186/s13048-014-0097-z

Cite this article as: Zhou et al:: SIRT1 activator (SRT1720) improves the follicle reserve and prolongs the ovarian lifespan of diet-induced obesity in female mice via activating SIRT1 and suppressing mTOR signaling. Journal of Ovarian Research 2014 7:97.

\section{Submit your next manuscript to BioMed Central and take full advantage of:}

- Convenient online submission

- Thorough peer review

- No space constraints or color figure charges

- Immediate publication on acceptance

- Inclusion in PubMed, CAS, Scopus and Google Scholar

- Research which is freely available for redistribution 